\title{
A Crystalline Mesoporous Coordination Copolymer with High Microporosity**
}

\author{
Kyoungmoo Koh, Antek G. Wong-Foy, and Adam J. Matzger*
}

Porous crystals constructed from the assembly of organic linking units with metal ions or metal clusters are proving to be an exciting class of materials with unprecedented properties and high potential for use in applications such as catalysis, ${ }^{[1]}$ gas storage, ${ }^{[2]}$ and separations. ${ }^{[3]}$ The underlying structure obtained from a given secondary building unit (SBU) with a multitopic ligand can be analyzed, at least with hindsight, as belonging to various nets. ${ }^{[4]}$ In some cases this approach has led to well-defined series with preserved topologies whose members vary in metrics or functionalities. $^{[5,6]}$ At the same time, it is clear that even a single linker with a given metal under the same reaction conditions can give rise to considerable structural diversity, as is illustrated by our recent application of polymer-induced heteronucleation to the discovery of three new phases based on the simple terephthalic acid linker/zinc nitrate system. ${ }^{[7]}$ Perhaps one lesson to be learned is that there is currently no single structure-predicting design scheme but rather sets of empirically derived default behaviors that can often be used to rationalize the outcome of an experiment. In the case of employing two different linkers possessing the same coordinating functionality, experimental data are lacking, and there is no basis for answering even the most basic question of phase composition. ${ }^{[8]}$

In broad terms we can expect two different behaviors in a crystalline mixed-linker coordination polymer. The default behavior for two components combined and allowed to crystallize is segregation; this behavior forms the basis of purification by crystallization. By contrast, the default behavior when monomers of similar reactivity are combined is random copolymerization. Therefore, it is interesting to contemplate whether in a porous crystal in which strong bonds reversibly assemble the framework, copolymerization patterns will dominate or if self-sorting crystallization will prevail. The former would represent an expeditious route to discover new porous solids. To investigate this question we undertook the synthesis of porous crystals based on two organic linkers of different topologies, namely, terephthalic

[*] Dr. K. Koh, Dr. A. G. Wong-Foy, Prof. A. J. Matzger

Department of Chemistry and the Macromolecular Science and

Engineering Program

University of Michigan

930 North University Ave, Ann Arbor, MI 48109-1055 (USA)

Fax: $(+1)$ 734-6715-8853

E-mail: matzger@umich.edu

[**; This work was supported by the US Department of Energy through the National Energy Technology Laboratory, under Award No. DEFG26-04NT42121.

Supporting information for this article is available on the WWW under http://www.angewandte.org or from the author. acid $\left(\mathrm{H}_{2} \mathrm{BDC}\right)$ and 1,3,5-tris(4-carboxyphenyl)benzene $\left(\mathrm{H}_{3} \mathrm{BTB}\right) . \mathrm{H}_{2} \mathrm{BDC}$ is the organic linker that, when combined with $\mathrm{Zn}^{\mathrm{II}}$, yields MOF-5, a stable cubic structure that is the best studied of the metal-organic frameworks. Using $\mathrm{H}_{3} \mathrm{BTB}$ under essentially identical synthetic conditions affords MOF177. This trigonal framework exhibits exceptional porosity and surface area and boasts the highest reported uptake of hydrogen gas in a physisorptive material. ${ }^{[2]}$ Combining $\mathrm{H}_{2} \mathrm{BDC}$ with $\mathrm{H}_{3} \mathrm{BTB}$, two ligands possessing aryl carboxylic acid coordinating groups, in the presence of zinc nitrate incorporates both components into a completely new type of structure that can be obtained to the exclusion of materials derived from either pure linker. Figure 1 illustrates the porous crystals produced by heating various ratios of $\mathrm{H}_{2} \mathrm{BDC}$ and $\mathrm{H}_{3} \mathrm{BTB}$ in the presence of excess $\mathrm{Zn}\left(\mathrm{NO}_{3}\right)_{2} \cdot 4 \mathrm{H}_{2} \mathrm{O}$ at $85^{\circ} \mathrm{C}$ for 2 days. Three distinct crystalline phases are observed as the mole fraction of $\mathrm{H}_{3} \mathrm{BTB}$ is increased. At low $\mathrm{H}_{3} \mathrm{BTB}$ concentrations, only MOF-5 crystals are formed; however, at a mole ratio of 4:1 $\left(\mathrm{H}_{2} \mathrm{BDC}: \mathrm{H}_{3} \mathrm{BTB}\right)$, a new needle-shaped phase is formed along with MOF-5. Increasing the $\mathrm{H}_{3} \mathrm{BTB}$ concentration leads to exclusive formation of the needleshaped phase, which according to powder X-ray diffraction (XRD) data is different from MOF-5 and MOF-177 (Figure S4 in the Supporting Information). A further increase of the $\mathrm{H}_{3} \mathrm{BTB}$ concentration results in MOF-177 forming as well. Finally, at $\mathrm{H}_{2} \mathrm{BDC}: \mathrm{H}_{3} \mathrm{BTB}$ mole ratios greater than or equal to 2:3, MOF-177 is the first product to crystallize out of solution.

A single-crystal X-ray diffraction study of the needleshaped crystals revealed a structure with one-dimensional hexagonal channels. The product crystallizes in the space group $P 6_{3} m$ and dramatically differs from the structures derived from the pure linkers. The framework of the material consists of $\mathrm{Zn}_{4} \mathrm{O}$ clusters linked together by two BDC and four BTB linkers arranged in an octahedral geometry (Figure 2a). Two BDC linkers are adjacent, leaving the other four positions occupied by BTB linkers, and these octahedra assemble into a structure containing both micropores and mesopores. This product is denoted as UMCM-1 (University of Michigan Crystalline Material-1). The micropores are found in cage-like structures constructed from six BDC linkers, five BTB linkers, and nine $\mathrm{Zn}_{4} \mathrm{O}$ clusters, and with an internal dimension of approximately $1.4 \mathrm{~nm} \times 1.7 \mathrm{~nm}$ (subtracting the van der Waals radii of the atoms, Figure $2 b$ ). Six such microporous cages assemble together in an edgesharing fashion to define the diameter of the mesopore, a 1D hexagonal channel $2.7 \mathrm{~nm} \times 3.2 \mathrm{~nm}$ (measured between pore walls, Figure $2 \mathrm{c}$ ). When van der Waals radii of the atoms are taken into account, the mesopore is $2.4 \mathrm{~nm} \times 2.9 \mathrm{~nm}$. Comparison of the bulk powder XRD pattern to that simulated 


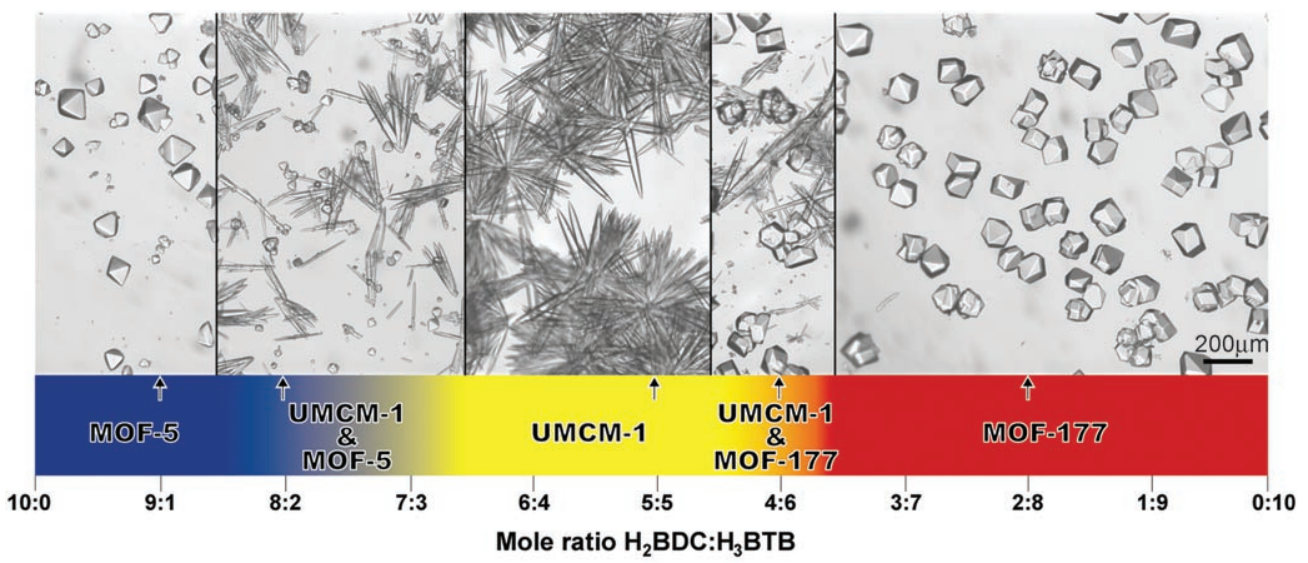

Figure 1. Heating solutions of zinc nitrate, $\mathrm{H}_{2} \mathrm{BDC}$, and $\mathrm{H}_{3} \mathrm{BTB}$ in $\mathrm{N}, \mathrm{N}$-diethylformamide at $85^{\circ} \mathrm{C}$ for 2 days yields three different phases depending on the ratio of the components in solution. An optimal mole ratio of $\mathrm{H}_{2} \mathrm{BDC}$ and $\mathrm{H}_{3}$ BTB to produce UMCM-1 is between $3: 2$ and $1: 1$. Arrows below each picture indicate the composition used to produce the crystals shown.

needles exchanged in $\mathrm{CH}_{2} \mathrm{Cl}_{2}$ and evacuated at room temperature supports the formulation of UMCM1 as $\mathrm{Zn}_{4} \mathrm{O}(\mathrm{BDC})(\mathrm{BTB})_{4 / 3}$.

Mesoporous coordination polymers (pore size $=$ 2-50 nm) are considerably more rare than microporous coordination polymers (pore size $<2 \mathrm{~nm}$ ), in part because as the size of the organic linker increases, the structural integrity of the resulting coordination polymer often decreases, which can result in collapse of the pore structure and a loss of crystallinity once the guest molecules (typically the solvent of synthesis and

a)
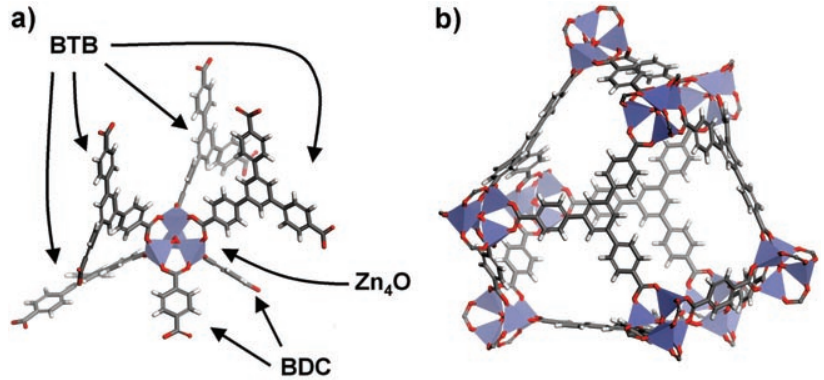

c)

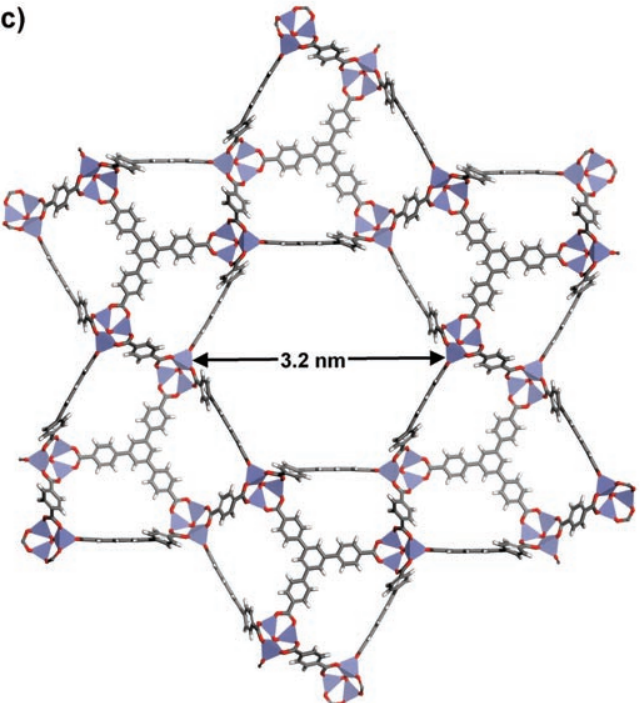

Figure 2. Structure of $U M C M-1:$ a) $A \mathrm{Zn}_{4} \mathrm{O}$ cluster coordinated to two $\mathrm{BDC}$ linkers and four BTB linkers. $\mathrm{Zn}_{4} \mathrm{O}$ clusters blue tetrahedra, $\mathrm{C}$ gray, $\mathrm{H}$ white, $\mathrm{O}$ red. b) A microporous cage constructed of six $\mathrm{BDC}$ linkers, five BTB linkers, and nine $\mathrm{Zn}_{4} \mathrm{O}$ clusters. c) Structure of UMCM-1 viewed along the $c$ axis illustrating the one-dimensional mesopore.

from single-crystal data confirms that a single, phase-pure material is formed for a mole ratio of $\mathrm{H}_{2} \mathrm{BDC}: \mathrm{H}_{3} \mathrm{BTB}$ between $3: 2$ and 1:1. Elemental analysis of as-synthesized synthetic components or by-products) are removed. Alternatively, interpenetration or catenation frequently occurs, which limits the formation of mesopores through partial pore occupation. To date, few examples of crystalline mesoporous coordination polymers have been reported, and those that have may be categorized according to the geometry of their mesopores. The first type have $1 \mathrm{D}$ mesoporous channels. ${ }^{[9,10]}$ In these materials porosity is derived mainly from the contribution of well-defined mesopores, and these do not exhibit the outstanding surface areas of their microporous counterparts. The second type of crystalline mesoporous coordination polymers exhibit mesoporous behavior owing to a network of cages found throughout the structure. These mesoporous cages are often restricted by small apertures or windows that prohibit very large molecules from accessing the space inside. ${ }^{[11-13]}$

The $\mathrm{N}_{2}$ sorption isotherm of UMCM-1 is shown in Figure $3 \mathrm{a}$. From the distinctive step in the region around $P / P_{0}=0.2$, the isotherm can be classified as type IV. ${ }^{[14]}$ In striking contrast to other mesoporous channel examples, however, UMCM-1 exhibits exceptionally high $\mathrm{N}_{2}$ uptake (ca. $1200 \mathrm{~cm}^{3} \mathrm{~g}^{-1}$ ) up to the first plateau, which is indicative of a substantial microporous contribution to the sorption behavior. Assuming monolayer coverage of $\mathrm{N}_{2}$ up to this first plateau and applying the Langmuir model, the apparent Langmuir surface area is calculated to be $4730 \mathrm{~m}^{2} \mathrm{~g}^{-1}$ (a similar treatment using the Brunauer-Emmer-Teller (BET) model affords a surface area of $4160 \mathrm{~m}^{2} \mathrm{~g}^{-1}$ ). Taking the second plateau $\left(>1400 \mathrm{~cm}^{3} \mathrm{~g}^{-1}\right)$ and applying the Langmuir model ${ }^{[12]}$ the apparent surface area is calculated to be $6500 \mathrm{~m}^{2} \mathrm{~g}^{-1}$; this value is significantly higher than that of any other material reported to date. A pore size distribution analysis of UMCM-1 by DFT methods utilizing Ar gas at $87 \mathrm{~K}$ reveals that there is a narrow distribution of micropores centered at about $1.4 \mathrm{~nm}$ and a narrow distribution of mesopores centered at about $3.1 \mathrm{~nm}$, which is in excellent agreement with the results from the from crystallography (Figure $3 \mathrm{~b}$ and Figure S3 in the Supporting Information). 
a)

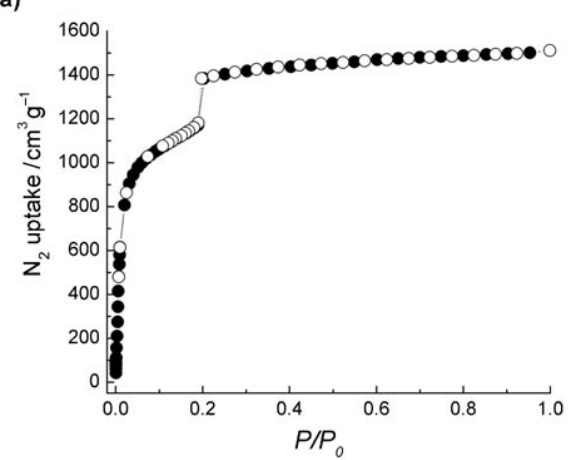

b)

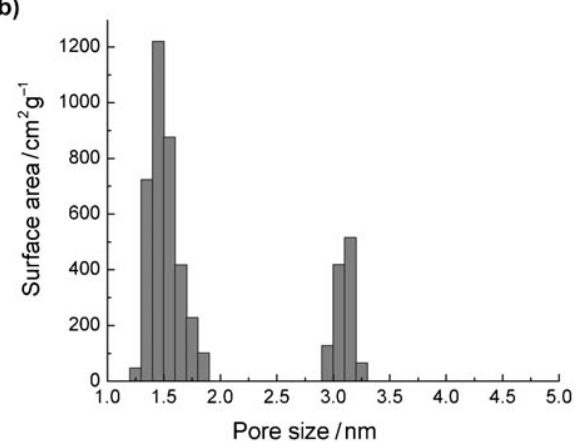

Figure 3. a) Nitrogen adsorption isotherm at $77 \mathrm{~K}$ for UMCM-1 (•, adsorption; $\mathrm{O}$, desorption). b) Pore size distribution calculated after fitting DFT models to argon gas adsorption data at $87 \mathrm{~K}$. coordinated metal cluster such as a $\mathrm{Zn}_{4} \mathrm{O}$ cluster attached to a ditopic linker and a tritopic linker, the probabilities for the formation for all possible coordination modes can be derived with the assumption that each carboxylic acid reacts at an equivalent rate (Figure S6 in the Supporting Information). Applying this analysis, the ratio of linkers in the initial reaction mixture gives rise to six regions with different coordination modes of highest probability (I-N in Figure 4). In region $\mathrm{L}$, the probability of the conformation of a cluster with two ditopic linkers in adjacent position and four tritopic linkers is highest, and this region corresponds to the synthetic conditions leading to UMCM-1. It should be noted that because a particular coordination mode has the highest probability of forming does not mean that a new crystalline phase will be obtained because the connectivity between clusters necessary to form a three-dimensional extended structure must also be satisfied by a thermodynamically reasonable structure. This analysis does, however, illuminate which combinations of linkers should be examined to reasonably sample phase space.

Several important findings are brought to light in this study. A strategy of using two different topologies of linkers possessing identical coordinating functionality for the production of new porous materials is demonstrated. For the case of UMCM-1, new properties emerge that exceed those of the materials derived from the pure linkers; this finding signals that coordination copolymerization is a method to advance the functionality of porous solids to new levels and lower production costs by making use of expensive linkers in

Thus, UMCM-1 is a material that for the first time possesses the most important attributes of both microporous coordination polymers (ultrahigh surface area) and mesoporous silicate/aluminosilicates (easily accessible mesopores). Although UMCM1 achieves record levels of porosity, the structure is remarkably robust. Thermogravimetric analysis showed minimal weight loss up to $400^{\circ} \mathrm{C}$ (Figure S1 in the Supporting Information) and no significant changes in the powder XRD pattern (Figure S4 in the Supporting Information). These measurements suggest that no dramatic structural changes take place, and indeed the $\mathrm{N}_{2}$

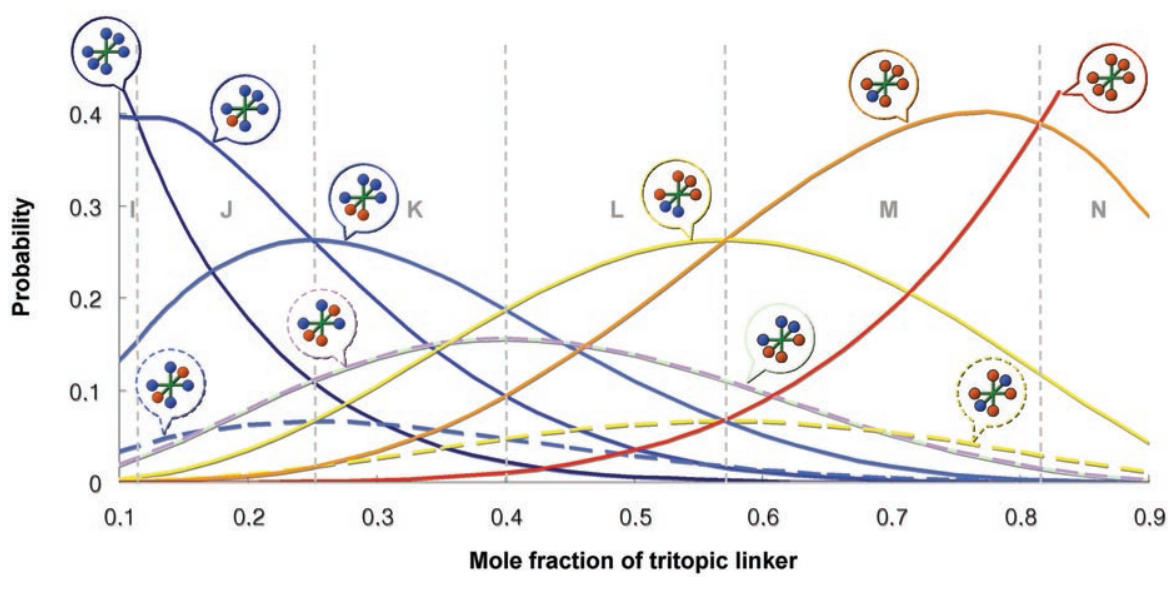

Figure 4. Probabilities for the formation for all possible coordination modes as a function of mole fraction of the tritopic linker. Ditopic linkers blue spheres, tritopic linkers red spheres. sorption isotherm after heating to $300^{\circ} \mathrm{C}$ for more than 3 hours is essentially unperturbed (Figure S5 in the Supporting Information), indicating that the framework of UMCM-1 is thermally stable.

Examination of the synthetic conditions leading to UMCM-1 reveals a strategy for favoring coordination copolymerization of two linkers. Although the network has a 1:1.33 ratio of BDC:BTB, adding the precursors in this stoichiometry does not lead to pure UMCM-1. A simple probabilistic argument illuminates this behavior. For an octahedrally combination with low cost ones to generate value-added products. Applying this method in a combinatorial fashion will undoubtedly unleash a flood of new materials with the vast supply of organic linker units currently available. Moreover, the ratios of linkers required for discovering new phases by this technique is predictable through a statistical treatment that can be readily extended to linkers with an arbitrary number of functional groups. Among the myriad new compositions this approach will enable, materials able to 
solve challenging and long-standing problems in gas storage, catalysis, and separations will likely be found.

Received: October 30, 2007

Published online: December 4, 2007

Keywords: coordination polymers - mesoporous materials . metal-organic frameworks - microporous materials . organic-inorganic hybrid composites

[1] C.-D. Wu, A. Hu, L. Zhang, W. Lin, J. Am. Chem. Soc. 2005, 127, $8940-8941$.

[2] A. G. Wong-Foy, A. J. Matzger, O. M. Yaghi, J. Am. Chem. Soc. 2006, 128, 3494-3495.

[3] B. Chen, C. Liang, J. Yang, D. S. Contreras, Y. L. Clancy, E. B. Lobkovsky, O. M. Yaghi, S. Dai, Angew. Chem. 2006, 118, $1418-$ 1421; Angew. Chem. Int. Ed. 2006, 45, 1390-1393.

[4] N. W. Ockwig, O. Delgado-Friedrichs, M. O'Keeffe, O. M. Yaghi, Acc. Chem. Res. 2005, 38, 176-182.

[5] M. Eddaoudi, J. Kim, N. Rosi, D. Vodak, J. Wachter, M. O'Keefe, O. M. Yaghi, Science 2002, 295, 469-472.

[6] X. Lin, J. Jia, X. Zhao, K. M. Thomas, A. J. Blake, G. S. Walker, N. R. Champness, P. Hubberstey, M. Schröder, Angew. Chem. 2006, 118, 7518-7524; Angew. Chem. Int. Ed. 2006, 45, 73587364 .
[7] A. L. Grzesiak, F. J. Uribe, N. W. Ockwig, O. M. Yaghi, A. J. Matzger, Angew. Chem. 2006, 118, 2615-2618; Angew. Chem. Int. Ed. 2006, 45, 2553-2556.

[8] Coordination copolymers derived from linkers with different functionality have been extensively studied. For an important early demonstration see: K. Seki, Chem. Commun. 2001, 14961497.

[9] X.-S. Wang, S. Ma, D. Sun, S. Parkin, H.-C. Zhou, J. Am. Chem. Soc. 2006, 128, 16474-16475.

[10] Q.-R. Fang, G.-S. Zhu, Z. Jin, Y.-Y. Ji, J.-W. Ye, M. Xue, H. Yang, Y. Wang, S.-L. Qiu, Angew. Chem. 2007, 119, 6758-6762; Angew. Chem. Int. Ed. 2007, 46, 6638-6642.

[11] A. C. Sudik, A. P. Côté, A. G. Wong-Foy, M. O'Keeffe, O. M. Yaghi, Angew. Chem. 2006, 118, 2590-2595; Angew. Chem. Int. Ed. 2006, 45, 2528-2533.

[12] Y. K. Park, S. B. Choi, H. Kim, K. Kim, B.-H. Won, K. Choi, J.-S. Choi, W.-S. Ahn, N. Won, S. Kim, D. H. Jung, S.-H. Choi, G.-H. Kim, S.-S. Cha, Y. H. Jhon, J. K. Yang, J. Kim, Angew. Chem. 2006, 118, 8378-8381; Angew. Chem. Int. Ed. 2007, 46, 82308233.

[13] G. Férey, C. Mellot-Draznieks, C. Serre, F. Millange, J. Dutour, S. Surblé, I. Margiolaki, Science 2005, 309, 2040-2042.

[14] K. S. W. Sing, D. H. Everett, R. A. W. Haul, L. Moscou, R. A. Pierotti, J. Rouquerol, T. Siemieniewska, Pure Appl. Chem. 1985, 57, 603-619. 